\title{
Utopismo, insurgência e espaço urbano: o "direito à cidade" lefebvriano e as Jornadas de Junho de 2013 no Brasil
}

\author{
Utopianism, insurgency and urban space: Lefebvre's "right \\ to the city" and the June 2013 Journeys in Brazil
}

Gustavo Souza Santos [l] Anete Marília Pereira [II]

\section{Resumo}

A metrópole paulistana foi palco e epicentro para a odisseia volátil, espontânea, difusa e reticulada que caracterizou as Jornadas de Junho de 2013 no Brasil. 0 espaço urbano tornou-se índice e plataforma de luta por sonhos sociais. Reflete-se, aqui, a associação entre essa mobilização e o "direito à cidade" em uma perspectiva de utopismo sobre o espaço urbano, a partir do ser e o agir sociopolítico. Como aporte a esta análise, examinou-se o conteúdo noticioso de jornais impressos de maior circulação no período, auditados pelo Instituto Verificador da Comunicação (IVC). 0 movimento revelou projetos de vida e país mobilizados na apropriação do espaço urbano para a luta em uma flexão utópica, como um signo socioespacial de insurgência e de desenvolvimento social.

Palavras-chave: Jornadas de Junho; direito à cidade; utopismo; utopia; espaço.

\begin{abstract}
The metropolis of São Paulo was the stage and epicenter for the volatile, spontaneous, diffused and reticulated odyssey that characterized the June 2013 Journeys in Brazil. The urban space has become an index and a platform to struggle for social dreams. In this article, we reflect on the association between this mobilization and the "right to the city" in a perspective of utopianism about the urban space, based on the being and on socio-political action. As a contribution to this study, we analyzed the news content of the printed newspapers with the highest circulation in the period, audited by the Communication Verification Institute (IVC). The movement revealed projects of life and country mobilized in the appropriation of the urban space for struggle in a utopian flexion, as a social-spatial sign of insurgency and social development.
\end{abstract}

Keywords: June Journeys; right to the city; utopianism; utopia; space. 


\section{Introdução}

Junho de 2013 ficou conhecido nos anais da história brasileira como um ano efervescente de mobilizações populares. As Jornadas de Junho caracterizaram uma odisseia insurgente que se difundiu sobre o território nacional de modo espontâneo, volátil, reticulado, solidário e cujas demandas foram tão amplas quanto seu escopo.

Os atos de junho de 2013 foram marcados por uma tríplice dinâmica: espacial, na retomada do espaço urbano com refletância on e off-line como signo de luta; sociopolítica, na mobilização em rede constituída a partir de territorialidades de insurgência; e, anamnésica, com o usufruto da memória como eixo de experiências e expectativas como índice de mobilização.

Tais dinâmicas se distribuíram em manifestações arregimentadas pelas redes sociais e caracterizadas por uma estrutura multiescalar e pluralmente solidária, de modo que motivações locais e regionais se tornaram pleitos fundamentalmente nacionais em um movimento uno e diverso. No escopo amplo de demandas, sonhos sociais flexionados entre projetos de vida e de país, numa odisseia utópica a aditivar os clamores mobilizados.

A partir do quadro teórico-crítico da tríplice dinâmica das Jornadas de Junho de 2013 no Brasil, reflete-se aqui sua associação com a teoria-projeto de direito à cidade, cunhada por Henri Lefebvre, e uma perspectiva de utopismo sobre o espaço urbano como ensejo de devires entre o ser e o agir sociopolítico. Como aporte metodológico à análise aqui empreendida, lança-se mão do discurso midiático, especificamente no exame do conteúdo noticioso de jornais impressos, dada a característica de frescor do tipológico periódico em fornecer o desencadeamento de fatos em contiguidade.

Desse modo, analisaram-se, aqui, notícias dos 3 veículos de maior circulação no período (Folha de S.Paulo, O Globo e Estadão), conforme auditoria do Instituto Verificador da Comunicação (IVC). 0 período compreendido pela auditoria do IVC foi 2012/2013, cuja cobertura abarca os acontecimentos de junho de 2013. 0 critério adotado, maior circulação, diz do potencial de cobertura jornalística, maior distribuição nacional e maior número de leitores.

\section{0 direito à cidade como pulsão utópica e signo de mobilização}

Epidemia de manifestações tem quase 1 protesto por hora. (Estadão, 30 jun 2013, p. 8)

Sem a predominância de bandeiras de partidos políticos, sindicatos ou entidades estudantis, os protestos lembraram as grandes mobilizações sociais do passado [...]. A diferença foi a força demonstrada pelas mídias sociais, decisivas não apenas para a mobilização como para o registro de cada detalhe em tempo real das manifestações, e a diversidade de palavras de ordem. (O Globo, 18 jun 2013, p. 3)

Mas a epidemia só ganhou força depois do dia 17, ao monopolizar o noticiário das grandes redes de televisão. (Estadão, 30 jun 2013, p. 8) 
Em sintonia com as últimas manifestações do país, brasileiros realizaram protestos ontem nas cidades de Nova York, Montreal, Dublin e Berlim. (O Globo, 17 jun 2013, p. 3)

Junho de 2013 ficou caracterizado por suas jornadas insurgentes que possuíam não apenas uma gramática particular, cujo escopo se amplificou em uma miríade territorializada de demandas, mas ainda por sua estética insurgente multiescalar, reticular e reflectante de modo on e off-line. A pluralidade de vozes adensou-se na multiplicidade de atos, cuja riqueza empírica está na dimensão simbólica permeadora e detonadora do intento reivindicatório em uma mobilização popular.

Os atos compreenderam 2,7 milhões de participantes distribuídos em 538 municípios dos 26 estados brasileiros mais o Distrito Federal, com flexões em 73 cidades de 25 países $^{1}$ nos 14 dias de manifestações. ${ }^{2}$ Os dados revelam que a envergadura das jornadas tinha característica territorial, ao cobrir não só o espaço nacional como também brasileiros residentes em outros países, e multiescalar pela difusão em proporções crescente e geométrica.

0 movimento surgiu particularizado, tendo a metrópole paulistana como palco e epicentro para a odisseia volátil, espontânea, difusa e reticulada que o caracterizou. Os signos, fixos e fluxos urbanos foram reelaborados em uma tríplice dinâmica: espacial, sociopolítica e anamnésica. Tal dinâmica e sua tessitura conferiram aos eventos de junho de 2013 uma gramática e uma estética particulares na produção de movimentos sociais.

0 noticiário dava conta de uma difusão adjetivada como epidêmica, cujo controle era dificultado por uma organização comunicacional voraz. Os intentos do Movimento Passe Livre (MPL) não eram novos, sua militância em torno da mobilidade urbana em grandes centros já era fatídica. Todavia, a carga reivindicatória em torno da negociata malsucedida entre prefeitura e militantes pelo aumento da passagem de ônibus deflagrou uma onda mobilizada.

A convocatória às ruas com o conclame "vem pra rua" 3 foi aditivada por cartazes, gritos e ocupação de vias e espaços públicos em uma onda cidadã com pulsão insurgente que se alastrava pelas rugosidades de cidades de pequeno, médio e grande portes, não sendo prerrogativa neural ou orgânica dos grandes centros. 0 espaço foi retomado em comparação ao movimento dos caras-pintadas, ${ }^{4}$ distante temporalmente em 20 anos.

Ruas, praças, arredores de instituições de governança, representações verticais do poder econômico, monumentos, vias e fluxos sanguíneos das cidades ocupados como sinal de participação sociopolítica e exercício citadino. Simultaneamente, fluxos e fixos recombinados como signos de insurgência. Esse mecanismo se reproduziu em ondulações por todos os estados do País, de modo reticulado e multiescalar (Santos e Cunha, 2018b).

As manifestações de junho de 2013 deram-se na particularidade da irradiação insurgente sem marcadores organizacionais específicos, embora os intentos do MPL constituíssem a fagulha detonadora do movimento. Apropriando-se da metáfora manifestante, 0 gigante acordou em um processo de capilaridade escalar, tendo ressonância territorial solidária (ibid., 2018c). 
A isso, destaca-se o aporte das redes sociais, arregimentadoras do processo, como aqui se evidencia:

0 papel das redes sociais (Facebook e Twitter) foi decisivo para a articulação dos discursos e para divulgar hora e local dos protestos. (Estadão, 30 jun 2013, p. 8)

[O Globo:] "Os protestos no Brasil não tinham líderes. Isso é uma qualidade ou um defeito?" [Castells:] "Claro que é uma qualidade. Não há cabeças para serem cortadas. Assim, as redes se espalham e alcançam novos espaços na internet e nas ruas. Não se trata, apenas, de redes na internet, mas redes presenciais". ( 0 Globo, 30 jun 2013, p. 17)

Um grupo de jovens passou a madrugada de ontem acampados na Avenida Delfim Moreira. [...] Na pauta do protesto, meIhorias em saúde e educação, crítica ao alto investimento para a Copa e a defesa da CPI do transporte público. (Estadão, 23 jun 2013, p. 10)

"Diálogo é um passo importante, mas sem ações concretas, não existe avanço", disse uma das líderes do movimento. (Estadão, 25 jun 2013, p. 6)

0 formato dos atos possuía a estética plausível de qualquer manifestação de natureza insurgente. No entanto, sua produção foi particularizada pelo modo como se organizou, espontaneamente e um movimento reticulado pela solidariedade territorial - em que os contextos pluralizados do território nacional guardam experiências e expectativas comuns de um único espaço nacional - e pelas redes de comunicação, via meios tradicionais e via comunicação alternativa de redes como Facebook e Twitter.

Nesse sentido, o movimento que já possuía trajetória reivindicatória e, logo, o conteúdo sociopolítico para se processar, passou a se dotar de flexões e extensões de escala ampliada. Os signos, sentidos e mobilizações produziram uma ativação territorial solidária, na qual dores e contextos de localidades remotas se interpolavam, gerando identificação e territorialidades de insurgência (Santos e Cunha, 2018a).

A contiguidade e a aparente indivisibilidade dos atos eram paradoxalmente acompanhadas pela pluralidade horizontal de demandas, clamores e contextos com os quais eram vocalizadas. 0 tema desencadeador de transporte público metabolizou-se em diversos outras pautas que compõem as estruturas do País e que se imiscuem ao cotidiano dos sujeitos presentes nas ruas e que assentiam aos atos.

A diversidade de pautas, a heterogeneidade de demandas e variedade de sentidos de luta podem ser observadas:

As manifestações que levaram milhares de pessoas às ruas do país, tinham reivindicações sociais diversas (saúde, educação, transporte), além de críticas contra a corrupção e um grito de guerra em comum: "Sem partidos". (Estadão, 21 jun 2013, p. 18)

Nos protestos, os pedidos de reforma do sistema de representação se misturam aos cartazes defendendo transporte mais barato, melhorias na saúde e na educação, transparência nos gastos públicos e combate à corrupção. (Estadão, 24 jun 2013, p. 7)

0 sentimento antipolítica não se restringia aos políticos, mas mirava em líderes do Executivo e Legislativo em todo o país. (Estadão, 21 jun 2013, p. 18)

"Calado não se muda nada". [...] "Muita coisa para melhorar". [...] "Tarifa foi só uma gotinha no oceano". [...] "As coisas 
têm de mudar neste país". [...] "Eles não estão nem aí para a gente". (Estadão, 21 jun 2013, pp. 19-20)

Atos retratam divórcio entre povo e Estado. (Estadão, 22 jun 2013, p. 16)

Embora, a temática do fato que foi o epicentro das manifestações fosse bastante definida, isto é, a mobilidade urbana e nela o transporte público do cidadão médio, pautas que refletem o arrocho social estavam presentes: saúde, educação, representação, transparência e corrupção. Direitos sociais e civis combinados em reivindicações politizadas, ao passo que com clamor popular livre e repetidamente declarado como apartidário e sem bandeiras de grupos de outras naturezas.

No signo da mobilidade urbana e nas vivências usuais e cotidianas do transporte público, está a existência deflagrada do cidadão, a construção da cotidianidade por meio do ir e vir, do trabalho, da atividade cidadã, da intersecção dos fluxos (transporte, econômicos, comunicacionais) com a própria realidade pessoal. E isso toca a produção de narrativas pessoais e coletivas, além dos ideários citadinos.

0 escopo ampliado do movimento concatenado em pautas plurais e polivalentes sobre a realidade social, econômica e política do país guarda ressonância direta com a percepção de direitos tanto sociais (pelo teor das reivindicações) e civis (pela gradação politizada). Contudo, essa percepção de direitos não se atrela a uma dimensão legalista per si, mas se traduz em visões simultaneamente pessoais e coletivizadas sobre a ordem socioespacial, representada pelas localidades multiescalares.

Essa evocação por direitos, vocalizada em gritos, cartazes e posts em "não é por
$\mathrm{R} \$ 0,20$, é por direitos", clamava por dignidade de vida na clara percepção de direitos conquistados não materializados e letargicamente conservados pela governança pública ou erodida por múltiplos interesses que achincalham o cotidiano do cidadão.

Tal arranjo tornou o objeto definido de pautas em torno do transporte público um signo de insurreição, uma vez que o ir e vir se vê comprometido e embaraçado em seu próprio eixo, paralisando seu pleno desenvolvimento. Assim, uma pauta torna-se epicentro para uma miríade sísmica de pautas com endereçamentos diversos deslizando sobre a materialidade das relações, o espaço urbano com seus fluxos e fixos.

Sendo um espaço urbano retomado, ocupado e incorporado como indumentária de protesto, o teor dos atos e esse construto de percepção-ação em torno de direitos, em cascata, tocam uma evocação lefebvriana:

As necessidades sociais têm um fundamento antropológico; opostas e complementares, compreendem as necessidades de segurança e de abertura, a necessidade de certeza e necessidade de aventura, a da organização do trabalho e a do jogo, as necessidades de previsibilidade e de imprevisto, de unidade e de diferença, de isolamento e de encontro, de trocas e de investimentos, de independência (e mesmo de solidão) e de comunicação, de imediaticidade e de perspectiva a longo prazo. 0 ser humano tem também a necessidade de acumular energias e a necessidade de gastá-las, e mesmo de desperdiçá-las no jogo. Tem necessidade de ver, de ouvir, de tocar, de degustar e a necessidade de reunir essas percepções num "mundo". (Lefebvre, 2016, p. 105) 
0 postulado lefebvriano adere-se à narrativa das Jornadas de Junho na medida em que estas em sua magnitude, estética e gramática próprias não representaram um discurso politizado burocrático, mas um diapasão simbólico ruidoso das pulsões que brotaram do atrito do clamor popular imiscuído em seus espaços situacionais - as vias em que trafegam, os espaços onde trabalham, são representados e gozam de lazer -, tal qual o espaço é substrato, indumentária e projeto de luta.

As alegorias de um gigante que acorda e o convite fortuito às ruas para a querela tiveram, no espaço urbano, a caixa de ressonância ideal para que o movimento se tornasse um germe e não um evento lido com a frequente lente utilitarista com a qual os movimentos sociais o são frequentemente. A cidade tornou-se, então, elemento basal de experiências, pois nela estão incrustados os objetos, as funções, os processos e as estruturas (Santos, 2002).

Em diálogo com junho de 2013 e Lefebvre (2016), pode-se acrescentar a perspectiva de Milton Santos (2002), ao conceber o espaço e sua dimensão como sistemas interligados de ações e objetos que se desenvolvem como um conjunto indissociável, solidário e contraditório, no qual operam temporalidades.

Desse modo, o usufruto do espaço pelos atos aqui sob exame - isto é, as dinâmicas socioespaciais que os caracterizaram - é sincrônico e diacrônico simultaneamente. A vivência do espaço como substrato e relação implica se articular entre objetos e ações ou objetividades e atividades, em um quadro único, como completaria Santos (ibid.).

Esse quadro indissociável, contraditório e solidário de ações e objetos é uma proposição cadente para entender os desdobramentos das dinâmicas das Jornadas de Junho no curso do "direito à cidade". Já que se quer considerar o espaço aqui como veículo da ação insurgente que está atrelada não só à raiz mobilizadora das manifestações, mas ao quadro teórico-crítico do dito lefebvriano. Há uma dimensão politizada que é fruto da vivência do espaço, solidário, dinâmico e contraditório.

Os objetos que designam o espaço não são compulsoriamente a materialidade técnica e domesticada, mas designam instrumentais simbólicos (ibid.). Trata-se de ícones, índices e símbolos incidentes sobre os sujeitos e incorporados em relações objetivas e subjetivas, cuja significação permite construir a realidade material e imaterial, vertendo sua existência e tecendo os sentidos entre autonomia, alteridade, coletividade, sociedade e, portanto, cidade. Ruas, monumentos, praças, edificações, a planificação viária e a infraestrutura urbana representam mais do que o ideário utilitário e cinza do espaço urbano. Nos tipológicos materiais está a experiência de significação cotidiana, na qual o trivial das atividades de trabalho, as narrativas pessoais, as relações interpessoais e toda a manufatura humana se entrecruzam e catalisam os sentidos coletivos da urbe.

É nesse espectro que as ações se inserem. São atos, eventos e movimentos desdobrados em práticas e projetos. A existência humana em si é uma ação desencadeadora de novas ações. A coletividade das relações urbanas é promovida pela articulação prática, simbólica, objetiva e subjetiva de uma série de ações que guardam propósito e efeito.

Assim:

A ação é o próprio do homem. Só o homem tem ação, porque só ele tem objetivo, finalidade. A natureza não tem ação 
porque ela é cega, não tem futuro. As ações humanas não se restringem aos indivíduos, incluindo, também, as empresas, as instituições. (lbid., p. 53)

Nessa interface da tipificação do espaço por Santos (2002) e da evocação sobre as necessidades humanas de Lefebvre (2016), pode-se caracterizar o devir humano como pulsão pela construção de si e da realidade, na qual esse processo construtor seja imbricado. $\mathrm{Ou}$ seja, ser, fazer, ir e vir são processos de construção da realidade, são projetos, são obras de vida (Castells, 1999; Hall, 2006).

As necessidades humanas são complexas na medida em que caracterizam forças propulsoras para a construção e manutenção da vida, ao passo que são instrumentais de reelaboração de sua própria condição. Isto é, balizadas pela realidade no tempo e no espaço, as necessidades são índices do real e, carregadas de percepções contíguas de mundo, constituem um germe que agencia e busca mudança, rearranjos e reestruturações de sua base e porvir (Santos e Cunha, 2018c).

No objeto catalisador da insurgência, estão atreladas necessidades humanas metabolizadas em percepções e visões da realidade, e que se tornam objetos detonadores de manifestações pelo arraigamento com a experiência cotidiana. No objeto catalisador e depois detonador está presente 0 anelo por um espaço real não compatível, não contíguo ou que não possui capacidade para comportar necessidades humanas feitas projetos idealizados.

Essas necessidades feitas projetos ideais possuem natureza pessoal, mas não deixa de se coletivizar e ampliar, na medida em que 0 rol de necessidades encontra ressonância e receptáculo na partilha territorializada do espaço e da experiência do tempo (Moya e Marques, 2012; Santos e Cunha, 2018a).

Ora, esse processo no qual a necessidade se torna projeto - pessoal, comunitário ou nacional - é vívido e, como tal, busca condições de execução e realização. 0 anelo por satisfação da necessidade e operacionalização do projeto gera atrito com a experiência cotidiana atroz, e esse atrito torna-se reativo. Atrição e reação que põem a natureza intersubjetiva de projetos de vida em movimento, um movimento que, privado de direitos e condições, se inflama e irrompe em querela.

Essa querela não se produz apenas na insurgência incontrolada ou violenta, como o imaginário costuma desenhar, mas é um ensejo sociopolítico de ensejo do presente pelo futuro, consideradas experiências e expectativas frustradas (Benjamin, 1994; Brandão, 1998). 0 produto metabolizado dessas necessidades no espaço ou na conjuntura sociopolítica de uma cidade, estado ou país é a criação de espaços de plenitude ou espaços de desenvolvimentos (Santos e Cunha, 2018a e 2018c).

A criação desses espaços de plenitude e desenvolvimento passa pela idealização que é a corporificação caudalosa das necessidades humanas que, complexas, encerram platitudes mais profundas do ser, do pertencer e do agir. Essa construção de pensamento é fundamental para compreender a relação entre as Jornadas de Junho de 2013, o "direito à cidade" e a noção de utopismo em dimensões social, política e culturalmente elaboradas.

Nessa perspectiva, Lefebvre (2016, pp. 113-114):

A essas necessidades antropológicas socialmente elaboradas (isto é, ora separadas, ora reunidas, aqui comprimidas e 
ali hipertrofiadas) acrescentam-se necessidades específicas, que não satisfazem os equipamentos comerciais e culturais que são mais ou menos parcimoniosamente levados em consideração pelos urbanistas. Trata-se da necessidade de uma atividade criadora, de obra (e não apenas de produtos e bens materiais consumíveis), necessidades de informação, simbolismo, de imaginário, de atividades lúdicas. [...] As necessidades urbanas específicas não seriam necessidades de lugares qualificados, lugares de simultaneidade de encontros [...]?

As necessidades que aqui se discutem, de fundo antropológico e socialmente reelaboradas no tempo e no espaço, requerem sua satisfação a partir de uma força criadora, que incide sobre a realidade adversa, ora construindo, ora desconstruindo, a partir do que se pode definir como objetos de necessidade. A atividade criadora metaboliza esses objetos em movimentos transformadores de incursão sobre a ordem social elaborada coletiva e politicamente.

0 teor desses objetos de necessidade não é limítrofe ao consumo material ou materializante, ou na mercadologia compulsória, mas se espraia nas necessidades ressignificadas e reificadas de informação, comunicação, ludicidade, significados e afetos. É no processo de satisfação desses objetos de necessidade que os sujeitos irrompem sua existência por meio da atividade criadora que dele processo emana, reivindicando e transformando o espaço em que se move e vive.

A partir de suas dinâmicas socioespaciais e políticas, junho de 2013 leva ao postulado de Lefebvre do "direito à cidade". As camadas de necessidades humanas aqui discutidas e as demandas vocalizadas nos atos têm proximidade sinérgica com o conceito lefebvriano na medida em que o conceito trata de uma revolução urbana que implica uma luta pelos benefícios da vida na cidade marcada por lastros segregacionistas e excludentes.

Nesse sentido, o "direito à cidade" não se esgota em um reforço jurídico de mais um direito ou na afirmação dos direitos à cartela de serviços urbanos. 0 conceito evoca um direito ou um índice de ação que implica o uso e a transformação do espaço. E, no espaço, suas experiências, práticas e as identidades, projetos e expectativas que ele comporta. É uma janela para a cidade como habitação politizada, imbricada à dignidade de vida e ideal de sociedade.

Harvey (2012, p. 74) esclarece:

A questão de que tipo de cidade queremos não pode ser divorciada do tipo de laços sociais, relação com a natureza, estilos de vida, tecnologias e valores estéticos desejamos. 0 direito à cidade está muito longe da liberdade individual de acesso a recursos urbanos: é o direito de mudar a nós mesmos pela mudança da cidade. Além disso, é um direito comum antes de individual já que esta transformação depende inevitavelmente do exercício de um poder coletivo de moldar o processo de urbanização. A liberdade de construir e reconstruir a cidade e a nós mesmos é, como procuro argumentar, um dos mais preciosos e negligenciados direitos humanos.

0 "direito à cidade" origina-se como crítica tenaz aos modos de produção e reprodução da vida social onde ela acontece, notadamente a cidade, e torna esse espaço uma radicação revolucionária, já que nomeia 0 próprio espaço como instrumental para uma 
ação transformadora da realidade. Os intentos do MPL, ao articularem militância sobre o transporte público e catalisarem sentimentos reticulados e submersos das cidades, da vida social, nas próprias cidades, nas ruas.

0 movimento esclarece:

A cidade é usada como arma para sua própria retomada: sabendo que o bloqueio de um mero cruzamento compromete toda a circulação, a população lança contra si mesma o sistema de transporte caótico das metrópoles, que prioriza 0 transporte individual e as deixa à beira de um colapso. Nesse processo, as pessoas assumem coletivamente as rédeas da organização de seu próprio cotidiano. (Movimento Passe Livre, 2013, p. 16)

Os efeitos que os atos do MPL - amplificados e superados em sua própria estrutura sociopolítica e estrutural - evocam o "direito à cidade" na medida em que o conteúdo da mobilização, das necessidades feitas insurgência, não se encerrou na perspectiva da urbanização ou na segregação em termos técnicos, mas na conjuntura polissêmica transcendente desse processo, a vida social e sua operacionalização crítica, coletiva e significante.

As reivindicações em torno de mobilidade urbana, saúde, educação, economia, justiça social e outros índices interpelam a produção da vida social na cidade, a quotidianidade e o desenvolvimento como discurso e experiência. Desse modo, "o pulso de insurgência das jornadas de junho é uma luta pelo direito à cidade, materializado na reivindicação pelos itens que compõem seu conclame e respaldado na ocupação espacial e no ensejo de transformação desse espaço, provedor de serviços, experiências e da vida em sociedade (Santos e Cunha, 2018c).
Entendendo o "direito à cidade" como um projeto político-espacial (Harvey, 2012) e as jornadas como insurgência territorializada (Santos e Cunha, 2018a), pode-se dizer que as necessidades mobilizadas em sua forma, conteúdo e repercussão são como espectro da sociedade em movimento, ou projeções de Brasis em uma noção de desenvolvimento, ou, ainda, performances sociopolíticas que reclamam lacunas sociais e de disparidades locais, regionais e nacionais.

A partir desse quadro crítico do "direito à cidade" diante dos atos em exame, convém retornar às proposições de Lefebvre (2016, pp. 119-120):

Os políticos têm seus sistemas de significações - as ideologias - que lhes permitem subordinar a suas estratégias os atos e acontecimentos sociais que são por eles influenciados. 0 humilde habitante tem seu sistema de significações (ou antes seu subsistema) a nível ecológico. 0 fato de habitar aqui ou ali comporta a recepção, a adoção, a transmissão de um determinado sistema [...]. 0 sistema de significações do habitante diz das suas passividades e das suas atividades; é recebido, porém modificado na prática. É percebido.

Aqui, o filósofo discute a disputa díspar entre sistemas políticos e os habitantes das cidades - que podem ser aqui entendidos como o cidadão em si - em papéis sociais de poder, sujeição e contrapoder. Ao evocar o sistema de significações em que ambos estão sujeitos, não só a relação de atrição entendida na insurgência e nos dispositivos sociopolíticos é evidenciada, mas a construção dessa ecologia de significados e percepções da ambivalente relação atividade-passividade do habitante. 
Essa relação atividade-passividade em que o sujeito se move em sistema no esteio urbano calcado de camadas de poder e política é importante para entender um processo duplo do qual Lefebvre (ibid.) chama a atenção para a compreensão axial do "direito à cidade": a transdução e a utopia. Nele, a transdução é o processo de transposição do trabalho conceitual à cartela empírica da realidade, na qual desliza a utopia tida como inventividade e conhecimento.

"Atualmente, quem não é utópico?" (ibid., p. 119). 0 "direito à cidade", entendido aqui como um projeto crítico, social, cultural, político e urbano, possui uma construção utópica na medida em que representa um ensejo social, uma aspiração comunitária, um fragor visionário de sociedade (originalmente no campo polissêmico do espaço) e que clama por direção.

Sargisson (2012, p. 8; tradução nossa) destaca que utopias:

[...] sempre expressam descontentamento com 0 agora e sempre sinalizam para direções alternativas. E, como tais, sempre se engajam em debates contemporâneos. Ao questionarem "o que há de errado com o mundo?", as utopias desempenham uma função diagnóstica. [...] Utopias são radicais em conteúdo e intenção. Elas desafiam as raízes dos sistemas socioeconômicos e políticos contemporâneos. E sua intenção é mudar o mundo.

0 conteúdo utópico procede como um ideário em projeto, uma pulsão ou um discurso constituído a partir das necessidades humanas no tempo e no espaço. E por, tratar de espacialidade e temporalidades, expostas às suas dinâmicas, a utopia interpela o real por meio de realidades imaginadas, sonhadas, produzidas em solo discursivo e consequentemente politizado. Utopias são, portanto, documentos (registram tempo e espaço), dispositivos (narrativa sociopolítica) e instrumentos (subversão, questionamento ou debate).

Para fortalecer esse prospecto:

Somente um entendimento de utopia que destrua antigas percepções e as transforma em algo novo [...] pode refletir adequadamente as preocupações, necessidades e desejos de descontentamentos com a contemporaneidade. Desse modo, a utopia crítica não apenas esquematiza, mas privilegia a mudança social em curso. E assim 0 faz abraçando imperfeições e incertezas. Utopias refletem e contribuem para debates de seus tempos. [....] Todas as utopias sempre se engajaram em questões contemporâneas. [...] Elas oferecem uma janela para a o pensamento político vigente e podem ser usadas como textos hermenêuticos ou interpretativos (sociais ou escritos). (lbid., p. 11; tradução nossa)

Ora, o "direito à cidade" lefebvriano modulado nos atos de junho de 2013 a partir de sua tríplice dinâmica - e o conteúdo detonador inicial das manifestações também - é um constructo utópico já que é simultaneamente um ensejo, um dispositivo e um instrumento de reflexão e debate comprometido com a transformação da realidade, e janela para o contemporâneo, extrapolando a textualidade social e hermenêutica e se transformando em agência.

0 utopismo urbano do "direito à cidade" deflagra a pulsão utópica do sujeito e da coletividade quando eventos, fenômenos e acontecimentos são colocados sob seu prisma, entre estes as jornadas em questão. Como pulsão participante de uma dialética da vida, 
da necessidade e do desejo, a estética textual, projetista e hermenêutica da utopia apresenta-se esteticamente como uma identidade de projeto ou de resistência (Castells, 1999; Hall, 2006).

0 conhecimento pode, portanto, construir e propor "modelos". Cada "objeto", nesse sentido, não é outra coisa além de um modelo de realidade urbana. No entanto, semelhante "realidade" não se tornará nunca manejável como uma coisa, nem se tornará instrumental. Mesmo para o conhecimento mais operatório. Que a cidade torne a ser o que foi: ato e obra de um pensamento complexo. (Lefebvre, 2016, p. 122)

Ao entender o conhecimento como propositor de modelos de realidade dotados de objetos de crítica e anelo, Lefebvre (ibid.) sinaliza a dimensão de conteúdo e atitude do "direito à cidade". Assim, a teoria-projeto em questão não prescinde da necessidade, mas flexiona-se em sua própria pulsão utópica, tornando-se uma utopia citadina.

As dinâmicas socioespaciais - rede, escala (Santos e Cunha, 2018a) e territorialidade (Santos e Cunha, 2018b) - verificadas em junho de 2013 denotam conteúdos utópicos em sua constituição de demandas, insurgência e nos sentidos do "direito à cidade". Contudo, esse conteúdo utópico acena conteúdos citadinos, uma vez que essa corporeidade instantânea e volátil de insurgência trafega nas raias de cidadania e politização.

A insurgência é uma ação coletiva. A utopia é uma articulação de núcleo coletivo como em um sonho social. 0 "direito à cidade" repousa na noção da coletividade representada no espaço urbano. Esse ideário coletivo tem viço na produção de identidades que, no solo da mobilização sociopolítica, se espraia como resistência e projeto (Castells, 1999).

É importante considerar:

Outro elemento catalisador do empreendimento de insurgência das jornadas de junho foi um aditivo essencial da experiência territorial: a(s) identidade(s). Nos eventos de junho, foi posta em fluxo uma identidade em conjunto, isto é, um cabedal identitário que dava roupagem ao movimento, com a qual os manifestantes e qualquer um que a endossasse podiam adotar e que continha as minúcias e variedades identitárias da própria diversidade identitária que caracteriza os cenários dos quais as manifestações integraram. (Santos e Cunha, 2018a)

Identidade é essencialmente um projeto de natureza intra e intersubjetiva, coletivizante e de expressão. Como tal, constitui-se indumentária para a ação e para a experiência social, bem como política. No limiar dos cenários evocados por junho de 2013, a diferença e a variabilidade afiavam as identidades postas em jogo insurgente. $E$, como um tecido alinhavado, estabelecia ligações com conteúdos utópicos e atitudinais de teor sociopolítico, socioespacial e anamnésico (Santos e Cunha, 2018c).

Retornando à Lefebvre (2016, p. 119):

Num período em que os ideólogos discorrem abundantemente sobre as estruturas, a desestruturação da cidade manifesta a profundidade dos fenômenos de desintegração (social, cultural). Esta sociedade, considerada globalmente, descobre que é lacunar [grifo do autor]. Entre os subsistemas e as estruturas consolidadas por diversos meios (coração, terror, persuasão ideológica) existem buracos, às vezes abismos. 
0 filósofo destaca que os signos da benesse e do progresso da sociedade global não encontraram significação plena no campo da experiência. Isto é, ficou evidente o desequilíbrio da construção do desenvolvimento professado como um credo (Rist, 2002) na quotidianidade lacunar, marcada por intempéries e instabilidades sociais, econômicas, políticas e urbanas.

Os buracos e abismos a que Lefebvre (2016) se refere se imbricam à forma, função, estrutura e processos da cidade, destravando uma miríade de contestações do desenvolvimento apregoado como induto messiânico ou indulgência última (Rist, 2002). Tais cenários fomentam construções utópicas e manifestações insurgentes como modalidades refletoras dessa funcionalidade cotidiana compulsória imposta pela realidade contemporânea.

Em Sargisson (2012), entende-se que o pensamento utópico delineia imagens alternativas do presente pelo esquadrinhamento de problemas centrais, alinhando imagens ideais e ameaças a esses mesmos ideais, em um processo de transdução narrativa e, que no contexto aqui discutido, pode se tornar política pelo caráter discursivo que a acompanha.

Nesse sentido, o conteúdo utópico revela não apenas um quadro de aspirações, mas um conjunto de temores ou reflexões sobre ameaças à vitalidade social e comunitária. Naturalmente, o intento utópico é composto de variáveis emocionais como a indignação e a esperança, conteúdos indispensáveis para a ação coletiva e detonadores da insurgência (Castells, 2013).

A ocupação das ruas - que é uma ocupação da forma, da função, da estrutura e dos processos desses espaços - é uma ocupação da ideia de país. A cólera insurgente que alimenta a mobilização é atrito, mas é ensejo de esperança. E a esperança repousa na ideia da luta, do resultado, do projeto, portanto, uma articulação simbólica utópica. Afinal, "a perda de esperança e de utopia significa perda de humanidade" (Sargisson, 2012, p. 14; tradução nossa).

Em jogo, projetos pessoais, vivências localizadas, lutas cotidianas e experiências diárias que ganham corpo no sentido solidário e coletivo desses projetos. Esses projetos ganham sentido de sustentação e objetividade dentro de um projeto de país (ou projetos). Quando os ideais nos quais se caminha se esfacelam, o caminho de reimaginá-los ativamente torna-se o programa da insurgência.

A partir desses pressupostos, convém analisar com Lefebvre (2016, p. 116):

Esses abismos não provêm do acaso. São também os lugares do possível. Contêm os elementos deste possível, elementos flutuantes ou diversos, não a força capaz de os reunir. Mais ainda: as ações estruturantes e o poder do vazio social tendem a impedir a ação e a simples presença de semelhante força. As instâncias do possível só podem ser realizadas no decorrer de uma metamorfose radical.

Esses abismos não casuais que erodem os planos de desenvolvimento e que erodem os projetos pessoais, coletivos e de país não representam em si a mudança ou contêm a direção. As lacunas só se tornam ingrediente insurgente a partir da combinação de forças sociais, políticas e simbólicas em negociações sistemáticas com os quadros hegemônicos.

"Nesse quadro, o pulso transformador de que a noção de direito (à cidade) - um direito de se pensar no plano das ideias e de se 
operacionalizar, no plano da ação - é alcançado com metamorfoses radicais" (Santos e Cunha, 2018a). A ideia de metamorfoses radicais pela via ação social e coletiva se coaduna à radicalidade que o intento e o conteúdo utópico evocam ao se constituir um texto social provocativo (Sargisson, 2012).

Os pontos de ação do tecido social com as forças citadinas, civis, políticas, públicas e privadas compõem essa teia de metamorfoses radicais. 0 conteúdo utópico assim como o "direito à cidade" em si não implicam uma força insólita e de narrativa que se compraz no signo poético (Sargent, 1994). Há, entretanto, o desenvolvimento de competências de engajamento.

É de Harvey (2012, p. 88) a sintetização:

Um passo na direção de unificar essas lutas é adotar o direito à cidade tanto como lema operacional quanto ideal político, justamente porque ele enfoca a questão de quem comanda a conexão necessária entre a urbanização e a utilização do produto excedente. A democratização deste direito e a construção de um amplo movimento social para fortalecer seu desígnio é imperativo, se os despossuídos pretendem tomar para si o controle que, há muito, Ihes tem sido negado, assim como se pretendem instituir novos modos de urbanização. Lefebvre estava certo ao insistir que a revolução tem de ser urbana, no sentido mais amplo deste termo, ou nada mais.

Estabelecendo linhas de diálogo entre Lefebvre (2016), Harvey (2012) e Sargisson (2012), é possível entender que a revolução utópica é uma etapa essencial para uma revolução social. Isso é possível porque tanto a mobilização popular que interpela pela insurgência e quanto a utopia que provoca pelo ensejo narrativo oferecem caminhos possíveis, planos realizáveis e pistas para a transformação objetificada na necessidade e no sonho ideal.

0 utopismo como um impulso humano dirigido por concepções e projeções de ideais se abriga nos recônditos de atividades e manifestações diversas na sociedade (Sargisson, 2012), como nos intentos sociopolíticos e no próprio "direito à cidade" lefebvriano. Essa dimensão é axiológica, portanto, para ações coletivas de natureza plural.

Retomando as Jornadas de Junho:

Na passeata, a busca de soluções coletivas. (Estadão, 23 jun 2013, p. 18).

[...] movimento pelo transporte despertou a luta por objetivos comuns. (Estadão, 23 jun 2013, p. 18)

A relação entre passagens caras e transporte precário ganhou facilmente uma analogia com impostos altos e serviços de saúde, educação e segurança ruins. De longe, a pauta parece extensa e vaga. Para os manifestantes - pessoas de todas as idades, predominantemente com ensino superior ou médio, no caso dos adolescentes -, parece lógica e viável, embora a luta seja longa. (Estadão, 23 jun 2013, p. 18)

A vez do povo desorganizado. (Folha, 30 de jun 2013, p. E10)

Há um desencontro entre os cidadãos e seus governantes. (Folha, 30 jun 2013, p. C7)

A química das massas é volátil, incendiária e instável, apesar de a maioria ser pacífica. (Folha, $1^{\circ}$ jul 2013, E10)

[...] o povo livre invadindo as ruas, sem um foco único. (Folha, $1^{\circ}$ jul 2013, A3) 
A substância da insurgência é incendiária, cuja metáfora mais alusiva seja a de abalo sísmico no qual um impacto é sentido sobre as estruturas durante sua ocorrência e mesmo depois em reverberações e rastros de sua passagem. A dimensão utópica possui semelhante ativação na medida em que seu conteúdo se radicaliza em sua expressão para projetar realidades alternativas às vigentes.

O noticiário deu conta de uma série de aditivos à essa substância insurgente e utópica: a consciência partilhada de problemas que afetam um número diverso de iguais, o entendimento de que medidas de luta são caminhos necessários e o são coletivamente, o diálogo dificultado entre suas representações, a sensação de desfaçatez nos sistemas e instituições de confiança, entre outros.

A carga insurgente é uma variável constituinte dessa dimensão projetista da utopia. Isso se explica pela aquiescência do ideal utópico que, ao imaginar projetos que transfigurem a realidade, o fazem mediante o fortalecimento da ideia em uma linguagem persuasiva cambiante em linguagem reflexiva, que explode contextos e oblitera radicalmente os limites do aceitável, do estabelecido e do cristalizado pela ideologia já afrouxada (Safatle, 2012).

Esse ideário incandescente ou explosivo é o capital central da politização da ação coletiva. Isto é, é a estética e a gramática das manifestações sociais que produzem, por meio da participação coalizão, sentidos políticos e, naturalmente, tessituras de desenvolvimento. $E$ o sujeito nesse processo, é indivíduo, é agente e é ele mesmo movimento social ao verter experiência, expectativa e ideal em capital sociopolítico (Touraine, 2009).
É preciso ressaltar que tanto o exercício utópico como o exercício insurgente têm aderência a partir de uma comunicação identitária comum capaz de catalisar emoção e ação e deflagrar atos concentrados. Em junho de 2013, essa identidade foi alinhavada a partir do vitrinismo dos atos que revelavam o país plural e comum e pela comunicação reticulada aditivada pelas redes sociais (Santos e Cunha, 2018b).

Os atos de 2013 podem, então, ser entendidos como pulsões utópicas e insurgentes na medida em que os sujeitos externalizavam sua própria identidade e as alinhavava com a de muitos, a partir da diferença plural, possibilitando um exercício catártico como o empreendido nas manifestações.

0 conteúdo noticioso dá conta desse processo revelando o rito insurgente confessado pelo exercício atitudinal:

“Podemos ser qualquer pessoa [...], uma pessoa sozinha não faz uma manifestação". (O Globo, 16 jun 2013, p. 6)

"As 20 mil pessoas que estão ali são estudantes, trabalhadores, pessoas que estão desempregadas, que apostam nessa luta como forma de ter uma cidade mais justa e alcançar seus direitos". ( 0 Globo, 16 jun 2013, p. 6)

Pelas ruas [...] um clamor popular por várias causas, de vários rostos, com várias ênfases. (Estadão, 21 jun 2013, p. 19)

Há muita luta por reconhecimento e identidade no momento atual, além de muito desejo de participação. (Estadão, 22 jun 2013, p. 2)

As dinâmicas do espaço permitem aos sujeitos elaborarem e desempenharem funções agregadoras ao espaço, a partir de suas 
próprias trajetórias em aspecto narrativo. Os atos de 2013 foram contagiosos a partir de uma solidariedade que é, ao mesmo tempo, compreensão dos extratos diversificados que integram o território, identificação com o outro e engajamento com a diversidade.

Assim, "cada lugar funcionava como recôndito e microdetonador de histórias, dinâmicas e relações. Naturalmente, a coletividade gestada é acompanhada de um exercício identitário" (Santos e Cunha, 2018a, p. 44). Esse prospecto se coaduna às identidades de resistência e projeto a que se referiu Castells (1999) ao categorizar processos identitários arrolados a comprometimentos e engajamentos na projeção do sujeito.

"Podemos ser qualquer pessoa", "uma pessoa sozinha não faz manifestação", "que apostam nessa luta", "um clamor popular por várias causas, de vários rostos, várias ênfases" e "muito desejo de participação", como os jornais relataram, demonstram esse engajamento identitário coletivizado, na medida em que multiplicam os esforços enquanto se adicionam os ensejos.

As jornadas tornaram-se, desse modo, "uma espécie de pacto que não concebe a diferença ou distância como limitações, mas pelo espaço em que sua ação se realiza e gera territorialidade, se anelam e se imbuem das mesmas pautas, tecendo um único tecido insurgente" (ibid., p. 44). A complexidade das sociedades denota maior complexidade em seu arranjo (Hall, 2006).

Essa complexidade nos arranjos da sociedade é percebida não apenas nas metamorfoses das mobilizações populares, como nos modos de se fazer política, mas na produção de sentidos do sujeito contemporâneo e produção de identidades. História e trajetória passam a ser alinhavadas com os elementos contextuais, espaciais e temporais, plasmados nos lugares e no encontro com o outro.

As Jornadas de Junho, mesmo em sua conjuntura complexa e fugidia, fornecem a leitura necessária para sua compreensão. Sua estética espontânea e gramática orgânica obteve coesão na medida em que metabolizou suas demandas, ações e projetos multiformes em uma tessitura identitária coletiva. Esse alinhavo identitário que suportou a mobilização particulariza define e se ativa no pleito da transformação social.

0 conteúdo utópico das iniciativas de incursão espacial calcados no aporte do "direito à cidade" demonstra "expressões identitárias fertilizadas pelas relações do sujeito com o espaço e a imbricação de significados emanados dele e reforçadas pela unidade promovida pelas territorialidades de insurgência" (Santos e Cunha, 2018a, p. 41), embebidas de utopia, promotoras de projetos coletivizados, marcadas por um programa insurgente.

Wilde (2003, p. 33) expressou que:

Um mapa do mundo que não inclua Utopia não merece ser olhado já que deixa de fora o único país no qual a humanidade está sempre desembarcando. E quando a humanidade chega ali, olha para 0 horizonte e, ao ver um país melhor, zarpa em sua busca. 0 progresso é a realização de utopias.

Na extremidade dos projetos de agência sociopolítica como as manifestações de 2013 e o "direito à cidade", estão construções utópicas que, por sua vez, como destacou Wilde (ibid.), acenam para o desenvolvimento. E esse processo se dá com base na rotina da mudança 
que se exerce nas imaginações sociais articuladas nas necessidades humanas.

Fica claro, assim, o papel do utopismo na formulação da participação social, achincalhada no exercício cidadão na encruzilhada (Carvalho, 2000), no espírito renovado da época e suas metamorfoses em curso (Ali, 2012), nas revoluções urbanas (Gomes, 2010), nas lutas por reconhecimento (Honneth, 2003), no poder das redes (Ribeiro, 2008) e na operação da memória (Neves, 2008).

Žižek (2012, p. 19) alerta para o silêncio violento de um novo começo para tratar dos questionamentos imediatistas das pulsões utópicas feitas exercício, como dos que aqui se examinam:

[...] devemos resistir precisamente a uma tradução assim apressada da energia das manifestações para um conjunto de demandas pragmáticas "concretas". Sim, os protestos realmente criaram um vazio que carrega consigo um embrião, uma abertura para o verdadeiro Novo. [...] A arte da política também é insistir numa exigência particular que, apesar de radicalmente "realista", perturba o núcleo da ideologia hegemônica, isto é, apesar de sem dúvida plausivel e legítima, é de facto impossível.

0 sociólogo trata do pragmatismo exacerbado de que pulsões sociopolíticas e utópicas são tratadas, originando uma leitura utilitarista e reducionista. Ao abordar esse aspecto, ele recorre ao silêncio que segue a detonação do conteúdo utópico e revolucionário. A violência desse silêncio aparenta não carregar mudanças ruidosas como sua manifestação plástica anterior, mas é portadora de um embrião gestado a partir das ressonâncias narrativas da ação.
Projetos de vida e projetos de país alinhavam-se na quotidianidade que não é experiência compulsória, mas luta, exercício catártico e disposição utópicas. Esse alinhavo é capaz de desafiar a ideologia hegemônica, construir visões de mundo renovadas, pensar a práxis do desenvolvimento. 0 próprio Lefebvre (2016, p. 119) tem a questão que desafia a ordem das coisas: "atualmente, quem não é utópico?".

\section{Considerações finais}

Projetos de vida e projetos de país foram parte das vocalizações nas Jornadas de Junho. A estética e a gramática das manifestações implicaram um processo onde a ocupação espacial gerou um mecanismo de solidariedade insurgente e identitária. A aderência a esse processo foi possibilitada pelo conteúdo utópico de que carregava, capaz de alinhavar indignação, ação e esperança.

0 "direito à cidade" lefebvriano evocado nas iniciativas de retomada socioespacial da cidade coaduna-se como um movimento de utopia, abarcando espacialidades e temporalidades dinâmicas e constituindo-se ensejos, dispositivos e instrumentos de ação e experiência social.

A utopia é desencadeadora de devires, já que articula realidades imaginadas e construídas no ideal do ensejo coletivo a partir do ser e do agir. Ao produzir uma narrativa, a utopia constrói uma trama que provoca debate e se metaboliza na ação coletiva, naturalmente insurgente ou integrada a iniciativas sociopolíticas. E é nesse processo que a utopia delineia tessituras de desenvolvimento social, sendo um signo de mobilização e desenvolvimento simultaneamente. 


\section{[I] https://orcid.org/0000-0002-9712-2690}

Centro Universitário Pitágoras, cursos de Comunicação Social - Publicidade e Propaganda, Psicologia, Engenharias Integradas e Engenharia Mecatrônica. Montes Claros, MG/Brasil.

gustavo.ccpv@gmail.com

[II] https://orcid.org/0000-0001-7084-7109.

Universidade Estadual de Montes Claros, Departamento de Geociências, Programas de Pós-Graduação em Geografia e em Desenvolvimento Social. Montes Claros, MG/Brasil.

anetemarilia@gmail.com

\section{Notas}

(1) Conforme apuração de http://g1.globo.com/brasil/protestos-2013/infografico/platb/. Acesso em: 30 ago 2018.

(2) Considera-se o período de 16 a 30 de junho de 2013 como a duração do que se conheceu como Jornadas de Junho em um movimento coeso. Atos anteriores ou subsequentes possuíram abordagens diferentes, embora imbuídas dos reflexos desse período específico.

(3) A expressão "vem pra rua" tornou-se etiqueta poética das manifestações. Sua origem é decorrente de uma campanha publicitária da empresa automobilística Fiat para a Copa das Confederações, na qual a convocatória das ruas possuía a conotação de torcer pela seleção brasileira de futebol. Conferir: https://www.youtube.com/watch?v=3AFMybxWiF0. Acesso em: 15 set 2018.

(4) Movimento estudantil que se tornou vitrine dos atos de pedido de impeachment do ex-presidente Fernando Collor de Melo, no Brasil.

\section{Referências}

ALI, T. (2012). "O espírito da época". In: HARVEY, D. et al. Occupy. Movimentos de protesto que tomaram as ruas. São Paulo, Boitempo/Carta Maior, pp. 65-72.

BENJAMIN, W. (1994). Obras escolhidas: magia e técnica, arte e política. São Paulo, Brasiliense.

BRANDÃO, C. R. (1998). "A primeira. Walter Benjamin. A dívida solidária com o passado". In: BRANDÃO, C.R. Memória Sertão: cenários, cenas, pessoas e gestos nos sertões de João Guimarães Rosa e de Manuelzão. São Paulo, Cone Sul / Uberaba, Editora Uniube, pp. 27-34.

CARVALHO, J. M. (2000). “Cidadania na encruzilhada”. In: BIGNOTTO, N. (org.). Pensar a república. Belo Horizonte, Editora UFMG, pp. 105-130. 
CASTELLS, M. (1999). O poder da identidade. São Paulo, Paz e Terra.

(2013). Redes de indignação e esperança: movimentos sociais na era da internet. Rio de Janeiro, Zahar.

GOMES, P. C. C. (2010). A condição urbana: ensaios de geopolítica da cidade. Rio de Janeiro, Bertrand Brasil.

HALL, S. (2006). A identidade cultural na pós-modernidade. Rio de Janeiro, DP\&A.

HARVEY, D. (2012). O Direito à Cidade. Lutas Sociais, Perdizes, n. 19, pp. 73-89, jul./dez.

HONNETH, A. (2003). Luta por reconhecimento. A gramática moral dos conflitos sociais. São Paulo, Editora 34.

LEFEBVRE, H. (2016). O direito à cidade. Itapevi, Nebli.

MOYA, E. e MARQUES, E. (2012). "Trocas sociais, apoios e mecanismos relacionais". In: MARQUES, E. (org.). Redes sociais no Brasil: sociabilidade, organizações civis e políticas públicas. Belo Horizonte, Fino Traço, cap. 4, pp. 81-110.

MOVIMENTO PASSE LIVRE (2013). “Não começou em Salvador, não vai terminar em São Paulo”. In: MARICATO, E. et al. Cidades rebeldes: Passe Livre e as manifestações que tomaram as ruas do Brasil. São Paulo, Boitempo e Carta Maior.

NEVES, F. R. (2008). Nova Hermenêutica Histórico-Crítica: revolução anamnésica e solidariedade histórica em Walter Benjamin. Contexto. Mossoró, v. 3, n. 3, pp. 103-110.

RIBEIRO, G. L. (2008). Poder, redes e ideologia no campo do desenvolvimento. Novos Estudos - Cebrap, São Paulo, n. 80, pp.109-125.

RIST, G. (2002). El desarrollo: historia de una creencia occidental. Madrid, España, Catarata.

SAFATLE, V. (2012). "Amar uma ideia". In: HARVEY, D. et al. Occupy. Movimentos de protesto que tomaram as ruas. São Paulo, Boitempo e Carta Maior, pp. 45-56.

SANTOS, G. S. e CUNHA, M. G. C. (2018a). As territorialidades insurgentes do gigante desperto: Jornadas de Junho de 2013 no Brasil e suas dinâmicas territoriais. Revista do Departamento de Geografia. São Paulo, v. 35, pp. 37-48.

(2018b). Entre protestos e fluxos: rede e escala nas jornadas de junho de 2013 no Brasil. Revista Elisée. Porangatu, v. 7, n. 1, pp. 71-84.

(2018c). "Não é por R\$̦ 0,20, é por direitos": dinâmicas de insurgência nas Jornadas de Junho de 2013 no Brasil. Caminhos de Geografia. Uberlândia, v. 19, n. 67, pp. 71-84.

SANTOS, M. (2002). A natureza do espaço: técnica e tempo, razão e emoção. São Paulo, Edusp

SARGENT, L. T. (1994). The three faces of utopianism revisited. Utopian Studies. Missouri, v. 5, n. 1, pp. 1-37.

SARGISSON, L. (2012). Fool's gold: utopianism in the twenty-first century. Hampshire, Palgrave Macmillan.

TOURAINE, A. (2009). "O sujeito como movimento social”. In: TOURAINE, A. Crítica da modernidade. Petrópolis, Vozes, pp. 247-268.

TRINDADE, T. A. (2012). Direito e cidadania: reflexões sobre o Direito à Cidade. Lua Nova. São Paulo, n. 87, pp. 139-165. 
WILDE, O. (2003). A alma do homem sob o socialismo. São Paulo, L\&PM.

ŽIŽEK, S. (2012). "O violento silêncio de um começo". In: HARVEY, D. et al. Occupy. Movimentos de protesto que tomaram as ruas. São Paulo, Boitempo e Carta Maior, pp. 15-26.

Texto recebido em 22/out/2018

Texto aprovado em 8/fev/2019 
